\title{
Clinical factors related to long-term administration of sorafenib in patients with hepatocellular carcinoma
}

This article was published in the following Dove Press journal:

Cancer Management and Research

17 December 2012

Number of times this article has been viewed

\author{
Shunsuke Nojiri' \\ Atsunori Kusakabe' \\ Kei Fujiwara' \\ Noboru Shinkai' \\ Kentaro Matsuura' \\ Etsuko lio' \\ Tomokatsu Miyaki' \\ Tomoyuki Nomura ${ }^{2}$ \\ Satoshi Sobue ${ }^{3}$ \\ Hitoshi Sano ${ }^{4}$ \\ Izumi Hasegawa ${ }^{5}$ \\ Tomoyoshi Ohno ${ }^{5}$ \\ Yoshitsugu Takahashi ${ }^{6}$ \\ Etsuro Orito 7 \\ Takashi Joh' \\ 'Department of Gastroenterology and \\ Metabolism, Nagoya City University \\ Graduate School of Medical Sciences, \\ Nagoya, ${ }^{2}$ Inabe General Hospital, \\ Inabe, ${ }^{3}$ Kasugai Municipal Hospital, \\ Kasugai, ${ }^{4}$ Tajimi Prefectural Hospital, \\ Tajimi, ${ }^{5}$ Social Chukyo Insurance \\ Hospital, Nagoya, ${ }^{6}$ Chita Kousei \\ Hospital, Aichi-ken, ${ }^{7}$ Nagoya Daini Red \\ Cross Hospital, Showa-ku, Japan
}

Correspondence: Shunsuke Nojiri Kawasumi I, Mizuho-cho, Mizuho-ku, Nagoya, Aichi, 467-860 I, Japan

Tel +8I 52853821 I

Fax +8I5 28520952

Email snojiri@med.nagoya-cu.ac.jp
Background: Sorafenib has been approved in the indication of unresectable hepatocellular carcinoma, but there are many cases in which administration of the drug is discontinued due to severe side effects. In this study, we compared the characteristics of patients who continued and discontinued sorafenib.

Methods: Ninety-six patients (75 men and 21 women) were initiated on sorafenib from July 2009 through September 2011. The patient characteristics of interest included gender, age, etiology, Child-Pugh classification, treatment history and frequency, and levels of $\alpha$-fetoprotein, des-gamma-carboxy prothrombin, aspartate amino acid transferase, and alanine aminotransferase. Duration of administration of sorafenib and reasons for its discontinuation were compared.

Results: Median overall survival was 11.8 months. Discontinuation of sorafenib within 90 days was identified as an independent prognostic factor for overall survival on multivariate analysis $(P<0.0001)$. Transarterial chemoembolization performed six times or more $(P=0.013)$ was also identified as an independent factor contributing to discontinuation of sorafenib within 90 days in multivariate analysis. Patients who received sorafenib for $\geq 90$ days had significantly longer overall survival than those who discontinued it $(P<0.0001)$.

Conclusion: Prolonged treatment with sorafenib is an important factor in achieving extended overall survival. We recommend starting sorafenib before latent liver damage has occurred as a result of too many transarterial chemoembolization procedures.

Keywords: sorafenib, hepatocellular continuation, discontinuation, efficacy

\section{Introduction}

In general, hepatocellular carcinoma in its early stages can be treated by surgical resection, radiofrequency ablation, ${ }^{1,2}$ or liver transplantation when there is a single nodule $\leq 5 \mathrm{~cm}$ or three nodules $\leq 3 \mathrm{~cm}$ (Milan criteria). ${ }^{3}$ However, many people are diagnosed in the advanced stages, when only transcatheter arterial infusion chemotherapy and transarterial chemoembolization are performed, ${ }^{4,5}$ but despite recently improved embolization devices, ${ }^{6}$ even these therapies have limited success in cases of vascular invasion or extrahepatic spread. ${ }^{7}$ Because hepatocellular carcinoma has a high recurrence rate, it is important to prevent secondary disease, and several therapies have been reported to prevent recurrence, including interferon, ${ }^{8}$ retinoids, ${ }^{9}$ and branched-chain amino acids. ${ }^{10}$

Recently, a number of molecularly targeted agents have been investigated throughout the world, ${ }^{11-13}$ and some agents are entering Phase II or III trials. ${ }^{14,15}$ Sorafenib inhibits the serine/threonine kinases, RAF-1and B-Raf, ${ }^{16,17}$ inhibits the tyrosine kinase activity of vascular endothelial growth factor receptors 1, 2, and 3 and 
platelet-derived growth factor receptor $\beta,{ }^{16,17}$ which has been shown to trigger production of reactive oxygen species and death of hepatocellular carcinoma cells. ${ }^{18}$

Sorafenib was approved to treat hepatocellular carcinoma in $2007,{ }^{19}$ and is used in patients with advanced stage disease. In two well known studies, sorafenib significantly increased survival time in patients with hepatocellular carcinoma, although there were absolute differences in survival time between the two patient populations because the definition of advanced disease differed between the two studies. ${ }^{20,21}$

Although administration of $800 \mathrm{mg}$ of sorafenib is recommended, there are many cases in which administration is discontinued or the dosage is reduced because of severe side effects. ${ }^{15,20,22}$ In this study, we demonstrated the therapeutic effects of sorafenib retrospectively and compared the characteristics of patients who continued and discontinued treatment with this agent.

\section{Materials and methods Patients}

We enrolled 96 patients who had started to receive the drug in our hospital or at one of six affiliated hospitals from July 2009 through September 2011 and were able to be observed for more than 90 days. The patient characteristics investigated included gender, age, etiology, Child-Pugh classification, treatment history and frequency, levels of $\alpha$-fetoprotein, des-gamma-carboxy prothrombin, aspartate amino acid transferase, and alanine aminotransferase, as well as treatment received prior to administration of sorafenib, eg, surgery, percutaneous ethanol injection therapy, percutaneous microwave coagulation therapy, radiofrequency ablation, transarterial chemoembolization, transcatheter arterial embolization, and/or transcatheter arterial infusion. The effectiveness of the treatments was evaluated according to modified Response Evaluation Criteria In Solid Tumors (RECIST) ${ }^{23}$ using an enhanced computed tomography scan every 3 months. Duration of administration of sorafenib was noted and the reasons for its discontinuation were identified.

\section{Treatment plan and toxicity evaluation}

Sorafenib was initiated at $800 \mathrm{mg} /$ day in two divided doses, ${ }^{24}$ and dose reduction was allowed for unacceptable adverse effects, ie, grade 3/4 toxicities, and treatment was continued until disease progression, development of intolerable drug toxicity, or patient refusal to continue taking the drug. Patients were followed up on an outpatient basis every 2-4 weeks. Adverse events were assessed according to the National Cancer Institute Common Toxicity Criteria for Adverse Events, version 4.0.

\section{Statistical analysis}

Overall survival was estimated using the Kaplan-Meier method, and differences in survival between the groups were compared using the log-rank test. Cox's proportional hazard model and logistic regression were used to examine likely prognostic factors in each group. The results were reported as hazard ratios with $95 \%$ confidence intervals. $P<0.05$ was considered to be statistically significant for all analyses. All statistical analyses were performed using JMP version 7.2 software (SAS Institute, Cary, NC).

\section{Results}

\section{Patient characteristics}

The 96 patients comprised 75 men and 21 women of mean age of $71.2 \pm 16.8$ (median 71 ) years (see Table 1). The etiology was hepatitis $\mathrm{C}$ virus in 56 , hepatitis $\mathrm{B}$ virus in 15, and others in 25. Median (range) levels of

Table I Baseline patient characteristics and previous therapy before administration of sorafenib

\begin{tabular}{|c|c|}
\hline Variable & Median (range) \\
\hline Age & 7| (52-87) \\
\hline Gender (M/F) & $75 / 21$ \\
\hline $\mathrm{HCV} / \mathrm{HBV} /$ others & $56 / 15 / 25$ \\
\hline Aspartate transaminase (U/L) & $54(19-165)$ \\
\hline Alanine aminotransferase $(\mathrm{U} / \mathrm{L})$ & $33(12-150)$ \\
\hline Platelets (per $\mu \mathrm{L}$ ) & $12(5-32)$ \\
\hline$\alpha$-fetoprotein $(\mathrm{ng} / \mathrm{mL})$ & $88.7(3.2-245,500)$ \\
\hline des-gamma-carboxy prothrombin $(\mathrm{mAU} / \mathrm{mL})$ & $559(5-75,000)$ \\
\hline Child-Pugh classification $(5 / 6 / 7)$ & $62 / 30 / 4$ \\
\hline $\mathrm{BCLC}$ stage $\mathrm{B} / \mathrm{C}$ & $37 / 59$ \\
\hline Extrahepatic spread $( \pm)$ & $27 / 69$ \\
\hline Macroscopic vascular invasion $( \pm)$ & $30 / 66$ \\
\hline ECOG performance status $(0 / 1 / 2)$ & $50 / 44 / 2$ \\
\hline Previous therapy & n (\%) \\
\hline Operation & $32(33)$ \\
\hline Percutaneous ethanol injection therapy & $\mathrm{II}(\mathrm{II})$ \\
\hline Percutaneous microwave coagulation therapy & $\mathrm{I}(\mathrm{I})$ \\
\hline Radiofrequency ablation & $42(44)$ \\
\hline $\mathrm{TA}(\mathrm{C}) \mathrm{E}$ & $72(75)$ \\
\hline Transcatheter arterial infusion & $19(20)$ \\
\hline Radiation & $5(5)$ \\
\hline \multicolumn{2}{|l|}{ Efficacy in all patients } \\
\hline Level of response & n (\%) \\
\hline $\mathrm{CR}$ & $0(0)$ \\
\hline PR & $13(14)$ \\
\hline SD & $31(32)$ \\
\hline PD & $30(3 I)$ \\
\hline Not evaluable & $22(23)$ \\
\hline Response rate & $14 \%$ \\
\hline Disease-control rate & $46 \%$ \\
\hline
\end{tabular}

Abbreviations: BCLC, Barcelona Clinic Liver Cancer; ECOG, Eastern Cooperative Oncology Group; HBV, hepatitis B virus; HCV, hepatitis C virus; $C R$, complete response; PR, partial response; $\mathrm{SD}$, stable disease; PD, progressive disease; TACE, transarterial chemoembolization. 
$\alpha$-fetoprotein, des-gamma-carboxy prothrombin, aspartate $(\mathrm{U} / \mathrm{L})$, and alanine aminotransferase $(\mathrm{U} / \mathrm{L})$ were 88.7 (3.2-245,500) ng/mL, 559 (5-75,000) mAU/mL, 54 (19-165) IU/L, and 33 (12-150) IU/L, respectively. Fifty, 44, and two patients had an Eastern Cooperative Oncology Group performance status of 0,1 , and 2, respectively. Child-Pugh classification was 5 in 62, 6 in 30, and 7 in four. Barcelona Clinic Liver Cancer (BCLC) staging was B in 37 and $\mathrm{C}$ in 59. Twenty-seven patients had metastatic disease in organs other than the liver. Prior medical history at the time of initiation of sorafenib therapy was surgery in 32 , percutaneous ethanol injection therapy in 11 , percutaneous microwave coagulation therapy in one, radiofrequency ablation in 42 , transarterial chemoembolization and/or transcatheter arterial embolization in 72 , transcatheter arterial infusion in 19 , and radiation in five cases.

\section{Efficacy, response, and disease control rates}

Median overall survival was 11.8 months. No patients had a complete response, 13 patients (14\%) had a partial response, and $31(32 \%)$ had stable disease (according to modified RECIST criteria), whereas 30 patients (31\%) had progressive disease and 22 patients were not evaluable. The disease control rate was $46 \%$ and the response rate was $14 \%$ (see Figure 1 and Table 1).

\section{Compliance with treatment}

The mean sorafenib dose was $800 \mathrm{mg}$ in 26 patients $(27 \%)$, $600 \mathrm{mg}$ in nine (9\%), $400 \mathrm{mg}$ in $46(48 \%)$, and $\leq 200 \mathrm{mg}$ in $15(16 \%)$. Because the median duration of treatment was 87 (range 2-737) days, we divided the patients into two

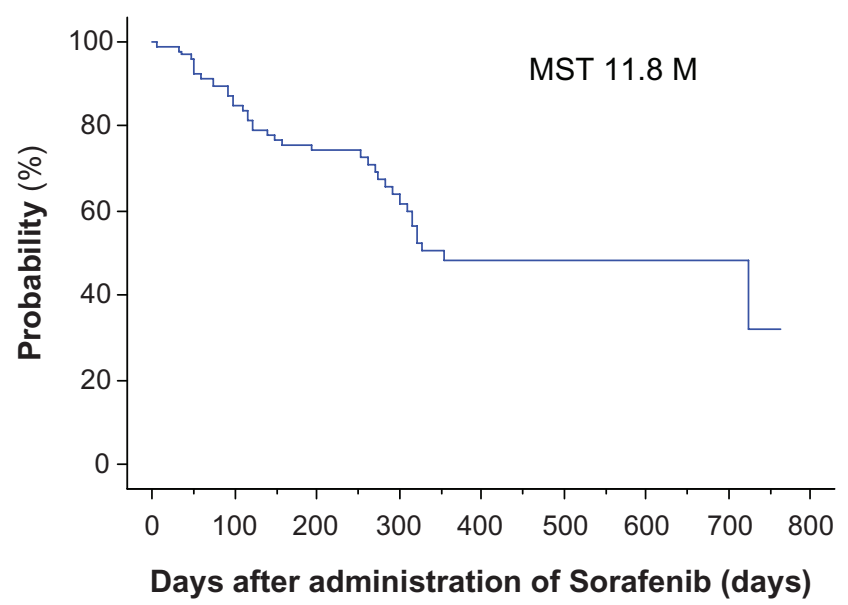

Figure I Overall survival for all patients. Note: Median overall survival was II.8 (range 7-763) days. groups, ie, one with $\geq 90$ days of treatment with sorafenib $(n=45)$ and another within 90 days of treatment with sorafenib ( $n=51)$, and examined factors influencing the patient's ability to take the drug on a longer-term basis (Table 2). Common reasons for discontinuation within 90 days were adverse events (40 patients) and radiologic progression $(\mathrm{n}=11)$. The adverse events were hand-foot skin reactions $(n=3)$, diarrhea $(n=3)$, general fatigue $(n=2)$, rash $(n=3)$, fever $(n=3)$, renal failure $(n=2)$, pancreatitis $(n=1)$, liver dysfunction $(n=15)$, and others $(n=8)$, whereas severe liver dysfunction included liver failure $(n=7)$, hepatic encephalopathy $(n=3)$, ascites $(n=3)$, elevation of aspartate or alanine aminotransferase $(n=1)$, and jaundice $(n=1)$.

\section{Prognostic factors for overall survival by univariate and multivariate analysis}

On univariate analysis, BCLC $(\mathrm{C})$ staging $(P=0.04)$, tumor volume $\geq 50 \%$ of the liver $(P<0.0001)$, macroscopic vascular invasion $(P=0.006)$, and discontinuation of sorafenib administration within 90 days $(P<0.0001)$ were significant prognostic factors, but only discontinuation of sorafenib within 90 days was identified as an independent prognostic factor contributing to overall survival on multivariate analysis $(P<0.0001$, Table 3$)$.

\section{Relationship between administration for $\geq 90$ days and overall survival}

In the group that continued on sorafenib for $\geq 90$ days, overall survival was significantly longer than in the group that discontinued sorafenib within 90 days $(P<0.0001)$, and the same relationship was found in the 61 patients who had their dose reduced to $400 \mathrm{mg}$ and $200 \mathrm{mg}(P=0.0026$,

Table 2 Reasons for discontinuation of sorafenib within 90 days

\begin{tabular}{ll}
\hline Adverse events without liver dysfunction & $\mathbf{3 6}$ \\
\hline Progressive disease & $1 \mathrm{II}$ \\
Hand-foot skin reaction & 3 \\
Diarrhea & 3 \\
General fatigue & 2 \\
Rash & 3 \\
Fever & 3 \\
Renal failure & 2 \\
Pancreatitis & 1 \\
Others & 8 \\
Liver dysfunction & 15 \\
\hline Liver failure & 7 \\
Hepatic encephalopathy & 3 \\
Ascites & 3 \\
Elevation of AST or ALT & 1 \\
Jaundice & 1 \\
\hline
\end{tabular}

Abbreviations: ALT, alanine transaminase; AST, aspartate transaminase. 
Table 3 Risk factors contributing to overall survival $(n=96)$

\begin{tabular}{|c|c|c|c|c|c|c|c|}
\hline & \multirow[t]{2}{*}{ Subgroup } & \multicolumn{3}{|c|}{ Univariate analysis } & \multicolumn{3}{|c|}{ Multivariate analysis } \\
\hline & & Risk ratio & $95 \% \mathrm{Cl}$ & $P$ value & Risk ratio & $95 \% \mathrm{Cl}$ & $P$ value \\
\hline Age & $\geq 7 \mid$ or $<7$ I & 0.74 & $0.39-1.4 \mid$ & 0.36 & & & \\
\hline Gender & Female & 1.53 & $0.94-2.51$ & 0.08 & & & \\
\hline Child-Pugh classification & $\geq 6$ or 5 & 0.54 & $0.28-1.04$ & 0.06 & & & \\
\hline$\alpha$-fetoprotein (ng/mL) & $<50$ or $\geq 50$ & 1.95 & $0.94-4.0$ & 0.71 & & & \\
\hline $\begin{array}{l}\text { Des-gamma-carboxy prothrombin } \\
(\mathrm{mAU} / \mathrm{mL})\end{array}$ & $<400$ or $\geq 400$ & 1.69 & $0.85-3.3$ & 0.13 & & & \\
\hline Etiology & $\mathrm{HCV}$, others & 0.74 & $0.39-1.4 \mid$ & 0.37 & & & \\
\hline PS & $\geq \mathrm{I}$ or 0 & 0.66 & $0.35-1.27$ & 0.22 & & & \\
\hline $\mathrm{BCLC}$ & C or B & 0.46 & $0.22-0.97$ & 0.04 & 0.96 & $0.38-2.45$ & 0.94 \\
\hline RFA & 0 or $\geq 1$ & 1.25 & $0.65-2.40$ & 0.51 & & & \\
\hline TACE & $<6$ or $\geq 6$ & 1.5 & $0.74-3.03$ & 0.26 & & & \\
\hline Tumor volume of liver & $<50 \%$ or $\geq 50 \%$ & $4.4 I$ & $2.24-8.69$ & $<0.000 \mathrm{I}$ & 1.70 & $0.77-3.74$ & 0.19 \\
\hline Macroscopic vascular invasion & None or + & 3.06 & $1.6 \mathrm{I}-5.82$ & 0.006 & 1.76 & $0.75-4.09$ & 0.19 \\
\hline Discontinuation & $<90$ or $\geq 90$ & 0.1 & $0.04-0.26$ & $<0.0001$ & 0.13 & $0.05-0.34$ & $<0.000 \mathrm{I}$ \\
\hline Extrahepatic spread & None or + & 1.61 & $0.83-3.13$ & 0.16 & & & \\
\hline
\end{tabular}

Abbreviations: BCLC, Barcelona Clinic Liver Cancer; $\mathrm{Cl}$, confidence interval; $\mathrm{CR}$, complete response; RFA, radiofrequency ablation; TACE, transarterial chemoembolization.

Figures 2 and 3). Therefore, we concluded that treatment with sorafenib for $\geq 90$ days achieves better overall survival, even at a reduced dose.

\section{Risk factors for discontinuation of sorafenib within 90 days by univariate and multivariate analysis}

To identify risk factors for discontinuation of sorafenib within 90 days, patients whose observed periods were less than 90 days were eliminated. The total number was 82 , with 45 being $\geq 90$ days and 37 being $<90$ days (Table 4). On univariate analysis, des-gamma-carboxy prothrombin $(\leq 400 \mathrm{mAU} / \mathrm{mL}, P=0.04)$, tumor

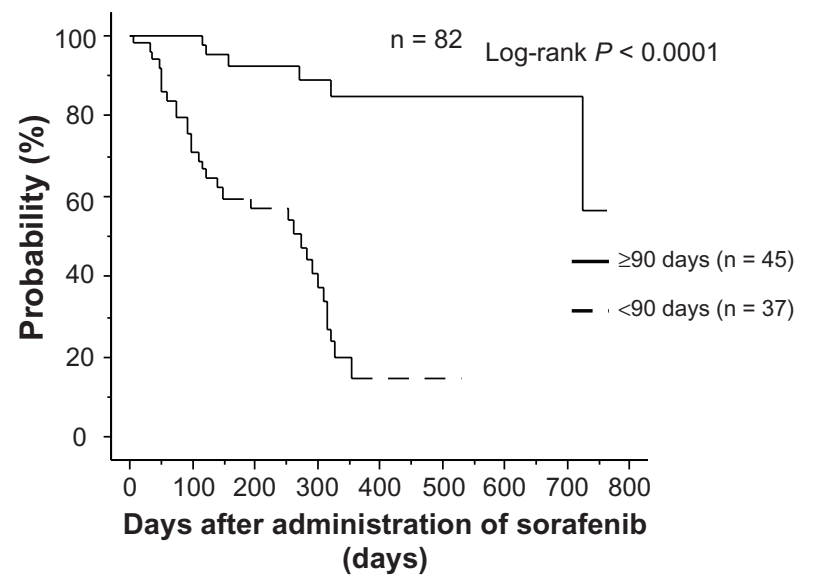

Figure 2 Relationship between continuation of administration and overall survival. Note: In the group that continued administration for $\geq 90$ days, overall survival was significantly higher than in the group that discontinued administration within 90 days. volume $\geq 50 \%$ of the liver $(P=0.02)$, macroscopic vascular invasion $(P=0.03)$, and six or more transarterial chemoembolizations $(P=0.02)$ were significant factors, and tumor volume $\geq 50 \%$ of the liver $(P=0.04)$ and six or more transarterial chemoembolizations $(P=0.013)$ were identified as independent risk factors on multivariate analysis.

\section{Discussion}

Sorafenib is considered a drug that should be used for advanced hepatocellular carcinoma, but there are no suitable criteria for treatment of hepatocellular carcinoma at this stage, because the treatment outcomes are affected by multiple variables, including liver function, patient performance status, and tumor stage. ${ }^{25,26}$

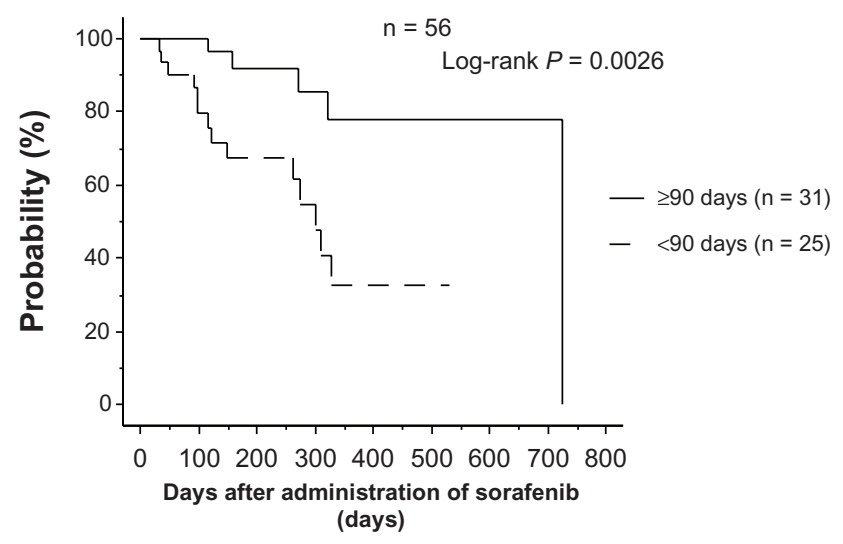

Figure 3 Relationship between continuation of administration and overall survival in patients receiving $200 \mathrm{mg}$ or $400 \mathrm{mg}$.

Note: In the group that continued administration for $\geq 90$ days, overall survival was significantly higher than in the group who discontinued administration within 90 days. 
Table 4 Risk factors contributing to discontinuation of sorafenib administration within 90 days $(n=82)$

\begin{tabular}{|c|c|c|c|c|c|c|c|}
\hline & \multirow[t]{2}{*}{ Subgroup } & \multicolumn{3}{|c|}{ Univariate analysis } & \multicolumn{3}{|c|}{ Multivariate analysis } \\
\hline & & Risk ratio & $95 \% \mathrm{Cl}$ & $P$ value & Risk ratio & $95 \% \mathrm{Cl}$ & $P$ value \\
\hline Child-Pugh classification & $\geq 6$ or 5 & 2.10 & $0.83-5.30$ & 0.11 & & & \\
\hline$\alpha$-fetoprotein (ng/mL) & $<50$ or $\geq 50$ & 0.55 & $0.22-1.35$ & 0.19 & & & \\
\hline $\mathrm{DCP}(\mathrm{mAU} / \mathrm{mL})$ & $<400$ or $\geq 400$ & 0.39 & $0.16-0.97$ & 0.04 & 0.59 & $0.22-1.60$ & 0.30 \\
\hline Radiofrequency ablation & 0 or $\geq 1$ & 0.78 & $0.32-1.88$ & 0.58 & & & \\
\hline Tumor volume of liver & $<50 \%$ or $\geq 50 \%$ & 0.08 & $0.01-0.69$ & 0.02 & 0.99 & $0.01-0.91$ & 0.04 \\
\hline Macroscopic vascular invasion & None or + & 0.33 & $0.12-0.87$ & 0.03 & 0.46 & $0.15-1.39$ & 0.17 \\
\hline TACE & $<6$ or $\geq 6$ & 0.26 & $0.08-0.83$ & 0.02 & 0.21 & $0.06-0.72$ & 0.013 \\
\hline Extrahepatic spread & None or + & 1.81 & $0.67-4.92$ & 0.24 & & & \\
\hline
\end{tabular}

Abbreviations: $\mathrm{Cl}$, confidence interval; DCP, des-gamma-carboxy prothrombin; TACE, transarterial chemoembolization.

Many trials have reported on the use of sorafenib to prevent hepatocellular carcinoma recurrence after treatment. ${ }^{27}$ Sorafenib is used with sirolimus or with inhibitors of mammalian target of rapamycin ${ }^{29}$ to reduce the risk of recurrence of hepatocellular carcinoma after liver transplantation, ${ }^{28}$ and it has been reported that such combination therapy can be effective. Some adjuvant therapy studies after curative treatment for hepatocellular carcinoma, such as the STORM (Sorafenib as adjuvant Treatment in the prevention Of Recurrence of hepatocellular carcinoMa) trial, are ongoing, ${ }^{27}$ and concurrent treatment of hepatocellular carcinoma with conventional transarterial chemoembolization and sorafenib has demonstrated a longer time to progression and possible efficacy. ${ }^{30,31}$ The overall median survival of our subjects was 11.8 months. Our data are slightly more robust than those of the Phase III SHARP (Sorafenib in Advanced Hepatocellular Carcinoma Assessment Randomized Protocol) trial (10.7 months $)^{20}$ and the tandem study in the Asia-Pacific region (6.5 months), probably because our study included a higher number of BCLC stage $\mathrm{B}$ patients than were included in the registration trials. ${ }^{21}$

Sorafenib has several side effects and is often discontinued when their grade becomes severe. Multikinase inhibitors such as sorafenib have unique clinicopathologic consequences, including hand-foot skin reactions and severe side effects. ${ }^{32-34}$ The severity of hand-foot skin reactions is dose-related and depends on the duration, dosage, and accumulation of the drug. ${ }^{35}$ Our data show that almost all patients had side effects, with about $40 \%$ of patients discontinuing sorafenib due to adverse events. However, some side effects may predict a response to sorafenib, such as early skin toxicity and diarrhea, ${ }^{22,36-38}$ and methods have been reported for evaluating efficacy and overall survival. ${ }^{39,40}$ No studies have reported the efficacy of treatment dose or duration because the Phase III trial for sorafenib used only $800 \mathrm{mg} .{ }^{20}$ Okuwaki et al reported late-onset progressive disease, indicating that prolonged treatment with sorafenib may be beneficial. ${ }^{41}$ In our data, several factors in univariate analysis, such as BCLC stage C, tumor volume $\geq 50 \%$ of the liver, macroscopic vascular invasion, and discontinuation of sorafenib within 90 days reduced overall survival, but discontinuation of sorafenib within 90 days was the only factor found to reduce overall survival in multivariate analysis. Patients able to take sorafenib for longer than 90 days had better overall survival than those who discontinued within 90 days, even if they could take only $400 \mathrm{mg}$ or less than $400 \mathrm{mg}$ because of side effects. Our data demonstrate the benefit of a long duration of treatment, even in cases of reduced dosage. Interestingly, upon further investigation of patients who could be observed for 90 days or more, multivariate analysis showed that a tumor volume occupying $\geq 50 \%$ of the liver and six or more transarterial chemoembolization procedures prior to initiation of sorafenib were significant prognostic indicators. Our data indicate that prolonged administration is an important factor in obtaining good overall survival, and is better started when the number of transarterial chemoembolizations is less than six. Many transarterial chemoembolization procedures can worsen liver function and, although the Child-Pugh score does not change, there might be latent liver damage.

Sorafenib is indicated for patients with BCLC stage $\mathrm{C}$ and transarterial chemoembolization is recommended for patients with BCLC stage $\mathrm{B},{ }^{7,42}$ so sorafenib is usually used in patients whose tumors are progressing despite locoregional therapy. We recommend starting sorafenib before latent liver damage has occurred as a result of too many transarterial chemoembolization procedures, and prolonged administration of sorafenib is important for long overall survival, even if the dose of sorafenib needs to be reduced because of side effects.

\section{Disclosure}

The authors declare that they do not have anything to disclose regarding funding or conflicts of interest with respect to this manuscript. 


\section{References}

1. Bruix J, Llovet JM. Prognostic prediction and treatment strategy in hepatocellular carcinoma. Hepatology. 2002;35:519-524.

2. Park KW, Park JW, Choi JI, et al. Survival analysis of 904 patients with hepatocellular carcinoma in a hepatitis B virus-endemic area. J Gastroenterol Hepatol. 2008;23:467-473.

3. Mazzaferro V, Regalia E, Doci R, et al. Liver transplantation for the treatment of small hepatocellular carcinomas in patients with cirrhosis. N Engl J Med. 1996;334:693-699.

4. Llovet JM, Real MI, Montana X, et al. Arterial embolisation or chemoembolisation versus symptomatic treatment in patients with unresectable hepatocellular carcinoma: a randomised controlled trial. Lancet. 2002;359:1734-1739.

5. Lo CM, Ngan H, Tso WK, et al. Randomized controlled trial of transarterial lipiodol chemoembolization for unresectable hepatocellular carcinoma. Hepatology. 2002;35:1164-1171.

6. Varela M, Real MI, Burrel M, et al. Chemoembolization of hepatocellular carcinoma with drug eluting beads: efficacy and doxorubicin pharmacokinetics. J Hepatol. 2007;46:474-481.

7. Bruix J, Sherman M. Management of hepatocellular carcinoma: an update. Hepatology. 2011;53:1020-1022.

8. Shiratori Y, Shiina S, Teratani T, et al. Interferon therapy after tumor ablation improves prognosis in patients with hepatocellular carcinoma associated with hepatitis C virus. Ann Intern Med. 2003;138: 299-306.

9. Muto Y, Moriwaki H, Ninomiya M, et al. Prevention of second primary tumors by an acyclic retinoid, polyprenoic acid, in patients with hepatocellular carcinoma. Hepatoma Prevention Study Group. N Engl J Med. 1996;334:1561-1567.

10. Muto Y, Sato S, Watanabe A, et al. Overweight and obesity increase the risk for liver cancer in patients with liver cirrhosis and long-term oral supplementation with branched-chain amino acid granules inhibits liver carcinogenesis in heavier patients with liver cirrhosis. Hepatol Res. 2006;35:204-214.

11. Semela D, Piguet AC, Kolev M, et al. Vascular remodeling and antitumoral effects of mTOR inhibition in a rat model of hepatocellular carcinoma. J Hepatol. 2007;46:840-848.

12. Dempke WC, Zippel R. Brivanib. A novel dual VEGF-R2/bFGF-R inhibitor. Anticancer Res. 2010;30:4477-4483.

13. Huynh H. Molecularly targeted therapy in hepatocellular carcinoma. Biochem Pharmacol. 2010;80:550-560.

14. Kudo M. Hepatocellular carcinoma 2009 and beyond: from the surveillance to molecular targeted therapy. Oncology. 2008;75 Suppl 1: $1-12$.

15. Villanueva A, Llovet JM. Targeted therapies for hepatocellular carcinoma. Gastroenterology. 2011;140:1410-1426.

16. Wilhelm SM, Carter C, Tang L, et al. BAY 43-9006 exhibits broad spectrum oral antitumor activity and targets the RAF/MEK/ERK pathway and receptor tyrosine kinases involved in tumor progression and angiogenesis. Cancer Res. 2004;64:7099-7109.

17. Chang YS, Adnane J, Trail PA, et al. Sorafenib (BAY 43-9006) inhibits tumor growth and vascularization and induces tumor apoptosis and hypoxia in RCC xenograft models. Cancer Chemother Pharmacol. 2007;59:561-574.

18. Coriat R, Nicco C, Chereau C, et al. Sorafenib-induced hepatocellular carcinoma cell death depends on reactive oxygen species production in vitro and in vivo. Mol Cancer Ther. 2012;11:2284-2293.

19. Wilhelm SM, Adnane L, Newell P, et al. Preclinical overview of sorafenib, a multikinase inhibitor that targets both Raf and VEGF and PDGF receptor tyrosine kinase signaling. Mol Cancer Ther. 2008;7:3129-3140.

20. Llovet JM, Ricci S, Mazzaferro V, et al. Sorafenib in advanced hepatocellular carcinoma. N Engl J Med. 2008;359:378-390.

21. Cheng AL, Kang YK, Chen Z, et al. Efficacy and safety of sorafenib in patients in the Asia-Pacific region with advanced hepatocellular carcinoma: a phase III randomised, double-blind, placebo-controlled trial. Lancet Oncol. 2009;10:25-34.
22. Otsuka T, Eguchi Y, Kawazoe S, et al. Skin toxicities and survival in advanced hepatocellular carcinoma patients treated with sorafenib. Hepatol Res. 2012;42:879-886.

23. Lencioni R, Llovet JM. Modified RECIST (mRECIST) assessment for hepatocellular carcinoma. Semin Liver Dis. 2010;30:52-60.

24. Shim JH, Park JW, Choi JI, et al. Practical efficacy of sorafenib monotherapy for advanced hepatocellular carcinoma patients in a Hepatitis B virus-endemic area. J Cancer Res Clin Oncol. 2009;135:617-625.

25. Han KH, Kudo M, Ye SL, et al. Asian consensus workshop report: expert consensus guideline for the management of intermediate and advanced hepatocellular carcinoma in Asia. Oncology. 2011;81 Suppl 1: $158-164$.

26. Llovet JM, Di Bisceglie AM, Bruix J, et al. Design and endpoints of clinical trials in hepatocellular carcinoma. $J$ Natl Cancer Inst. 2008;100:698-711.

27. Kudo M. Adjuvant therapy after curative treatment for hepatocellular carcinoma. Oncology. 2011;81 Suppl 1:50-55.

28. Weinmann A, Niederle IM, Koch S, et al. Sorafenib for recurrence of hepatocellular carcinoma after liver transplantation. Dig Liver Dis. 2012;44:432-437.

29. Gomez-Martin C, Bustamante J, Castroagudin JF, et al. Efficacy and safety of sorafenib in combination with mammalian target of rapamycin inhibitors for recurrent hepatocellular carcinoma after liver transplantation. Liver Transpl. 2012;18:45-52.

30. Sansonno D, Lauletta G, Russi S, et al. Transarterial chemoembolization plus sorafenib: a sequential therapeutic scheme for HCV-related intermediate-stage hepatocellular carcinoma: a randomized clinical trial. Oncologist. 2012;17:359-366.

31. Park JW, Koh YH, Kim HB, et al. Phase II study of concurrent transarterial chemoembolization and sorafenib in patients with unresectable hepatocellular carcinoma. J Hepatol. 2012;56:1336-1342.

32. Lacouture ME, Reilly LM, Gerami P, et al. Hand foot skin reaction in cancer patients treated with the multikinase inhibitors sorafenib and sunitinib. Ann Oncol. 2008;19:1955-1961.

33. Lacouture ME, Wu S, Robert C, et al. Evolving strategies for the management of hand-foot skin reaction associated with the multitargeted kinase inhibitors sorafenib and sunitinib. Oncologist. 2008;13: 1001-1011.

34. Rombola F, Caravetta A, Mollo F, et al. Sorafenib, risk of bleeding and spontaneous rupture of hepatocellular carcinoma. A clinical case. Acta Medica (Hradec Kralove). 2011;54:177-179.

35. Boudou-Rouquette P, Ropert S, Mir O, et al. Variability of sorafenib toxicity and exposure over time: a pharmacokinetic/pharmacodynamic analysis. Oncologist. 2012;17:1204-1212.

36. Vincenzi B, Santini D, Russo A, et al. Early skin toxicity as a predictive factor for tumor control in hepatocellular carcinoma patients treated with sorafenib. Oncologist. 2010;15:85-92.

37. Bettinger D, Schultheiss M, Knuppel E, et al. Diarrhea predicts a positive response to sorafenib in patients with advanced hepatocellular carcinoma. Hepatology. 2012;56:789-790.

38. Zhao Y, Yang M, Qi X, et al. Drug-related adverse events may predict efficacy in sorafenib therapy for hepatocellular carcinoma. Hepatology. 2012;56:790-791.

39. Horger M, Lauer UM, Schraml C, et al. Early MRI response monitoring of patients with advanced hepatocellular carcinoma under treatment with the multikinase inhibitor sorafenib. BMC Cancer. 2009;9:208.

40. Lee JH, Park JY, Kim do Y, et al. Prognostic value of 18F-FDG PET for hepatocellular carcinoma patients treated with sorafenib. Liver Int. 2011;31:1144-1149.

41. Okuwaki Y, Nakazawa T, Hidaka H, et al. Late-onset benefit in progressive advanced hepatocellular carcinoma with continued sorafenib therapy: a case report. J Med Case Rep. 2012;6:38.

42. EASL-EORTC clinical practice guidelines: management of hepatocellular carcinoma. J Hepatol. 2012;56:908-943. 


\section{Publish your work in this journal}

Cancer Management and Research is an international, peer-reviewed open access journal focusing on cancer research and the optimal use of preventative and integrated treatment interventions to achieve improved outcomes, enhanced survival and quality of life for the cancer patient The journal welcomes original research, clinical \& epidemiological studies, reviews \& evaluations, guidelines, expert opinion \& commentary, case reports \& extended reports. The manuscript management system is completely online and includes a very quick and fair peerreview system, which is all easy to use. Visit http://www.dovepress.com/ testimonials.php to read real quotes from published authors.

Submit your manuscript here: http://www.dovepress.com/cancer-management-and-research-journal 